\title{
Toxic anterior-segment syndrome (TASS)
}

This article was published in the following Dove Press journal:

Clinical Ophthalmology

9 October 2014

Number of times this article has been viewed

\author{
Servet Cetinkaya' \\ Zeynep Dadaci ${ }^{2}$ \\ Hüsamettin Aksoy ${ }^{3}$ \\ Nursen Oncel Acir ${ }^{2}$ \\ Halil Ibrahim Yener ${ }^{4}$ \\ Ekrem Kadioglu ${ }^{5}$ \\ 'Ophthalmology Clinics, Turkish \\ Red Crescent Hospital, Konya, \\ 2Department of Ophthalmology, \\ Faculty of Medicine, Mevlana \\ University, Konya, ${ }^{3}$ Ophthalmology \\ Clinics, Karaman State Hospital, \\ Karaman, ${ }^{4}$ Konya Eye Center Hospital, \\ Konya, ${ }^{5}$ Ophthalmology Clinics, \\ Beyhekim State Hospital, Konya, \\ Turkey
}

Video abstract

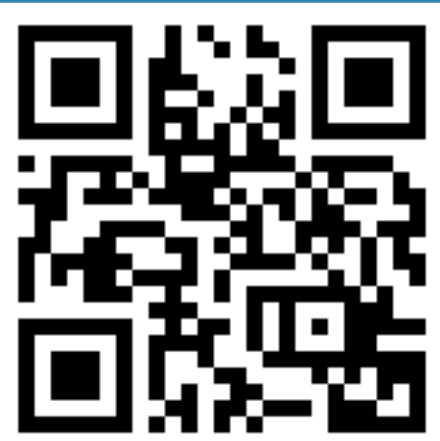

Point your SmartPhone at the code above. If you have a QR code reader the video abstract will appear. Or use:

http://dvpr.es/In4ScrU

Correspondence: Servet Cetinkaya Ophthalmology Clinics, Turkish Red Crescent Hospital (Kizilay Hastanesi), 15 Taskapu Medrese Sok, Sukran Mah, Meram, Konya 42200, Turkey

Tel +905322303421

$\mathrm{Fax}+903323519702$

Email drservet42@gmail.com
Purpose: To evaluate the clinical findings and courses of five patients who developed toxic anterior-segment syndrome (TASS) after cataract surgery and investigate the cause.

Materials and methods: In May 2010, on the same day, ten patients were operated on by the same surgeon. Five of these patients developed TASS postoperatively.

Results: Patients had blurred-vision complaints on the first day after the operation, but no pain. They had different degrees of diffuse corneal edema, anterior-chamber reaction, fibrin, hypopyon, iris atrophies, and dilated pupils. Their vision decreased significantly, and their intraocular pressures increased. Both anti-inflammatory and antiglaucomatous therapies were commenced. Corneal edema and inflammation resolved in three cases; however, penetrating keratoplasty was needed for two cases and additional trabeculectomy was needed for one case. Although full investigations were undertaken at all steps, we could not find the causative agent.

Conclusion: TASS is a preventable complication of anterior-segment surgery. Recognition of TASS, differentiating it from endophthalmitis, and starting treatment immediately is important. Controlling all steps in surgery, cleaning and sterilization of the instruments, and training nurses and other operation teams will help us in the prevention of TASS.

Keywords: cataract, phacoemulsification, TASS, corneal edema, inflammation

\section{Introduction}

Toxic anterior-segment syndrome (TASS) is an acute, sterile, inflammatory reaction, characterized by diffuse limbus-to-limbus corneal edema due to endothelial layer damage, fibrinous reaction in the anterior chamber and hypopyon due to breakdown of the blood-aqueous barrier, dilated pupils, and glaucoma due to damage to the iris and trabecular meshwork. It is a reaction against a toxic substance, occurring after any anterior-segment surgery, and usually presents as outbreaks. ${ }^{1-4}$ It generally presents within 12-48 hours after the surgery, and the main complaint of the patient is visual loss. ${ }^{5,6}$ Inflammation is restricted to the anterior segment; there is no posterior-segment involvement. It must be differentiated from endophthalmitis. Intense topical steroidal agents are used in the treatment; in most cases, the inflammation is resolved with this therapy, but in severe cases there may be permanent visual loss. ${ }^{4,6,7}$

There are many substances causing TASS, which include residues left behind by items used during cleaning and sterilization of surgical instruments, irrigating solutions with incorrect $\mathrm{pH}$, osmolarity or ionic composition, preservatives, stabilizing agents, denatured ophthalmic viscosurgical devices, endotoxins, heavy metals, intraocular medications at toxic doses, and ointments. ${ }^{8-11}$

In this study, we evaluated the clinical findings and courses of five patients who had undergone cataract surgery and developed TASS after the surgery, and investigated the possible causes. 


\section{Materials and methods}

The study protocol was approved by the local ethics committee. Informed consent was obtained from the patients. The study was carried out according to the tenets of the Declaration of Helsinki.

In May 2010, on the same day, ten patients were operated on by a single surgeon (SC). All of the patients had had their other eye operated on 1 week previously, and they had no problem with that eye. The same surgeon performed these operations at the same hospital. Nothing changed. Preoperative preparations and medications used were not different from the previous surgery. The surgical technique used was the same. Before the operation for pupil dilatation, Mydfrin ${ }^{\circledR}$ (phenylephrine hydrochloride 2.5\%) and Tropamide (tropicamide $0.5 \%$ ) drops were used. Under sub-Tenon's anesthesia (Marcaine $^{\circledR}$; bupivacaine $0.5 \%, 2 \mathrm{~mL}$ ), after clear corneal incision, the anterior chamber was filled with a dispersive viscoelastic material (Easy Visc; hydroxypropyl methylcellulose $2 \%$ ), and then continuous curvilinear capsulorhexis was performed. Then, a side-port incision was performed. After hydrodissection and hydrodelineation, the nucleus was emulsified by using the stop-and-chop technique. After cortex elimination, capsular polishing was done. After a cohesive viscoelastic material (Easy-Luron; Na hyaluronate $16 \mathrm{mg}$ ) injection, a foldable posterior-chamber intraocular lens (IOL; Acriva; acrylate monomer) was implanted. For prophylaxis of endophthalmitis, $0.1 \mathrm{~mL}$ moxifloxacin $0.5 \%$ was administered intracamerally. No ointment was used. After surgery, topical antibiotic (ofloxacin $0.3 \%$ ) and steroid (prednisolone acetate $1 \%$ ) treatment was advised four times a day.

The medications and instruments used intraoperatively were not different from those used routinely. Types of cataracts were similar; the energy used and the length of surgery were not different. No dyes, rings, pupil stretchers, or any other device was used. No intraoperative complications occurred. There had been no recent changes in the operation room, sterilization devices, or in the operative team, and the surgeon had no other cases of TASS beforehand or later on.

\section{Results}

On the first day following the surgeries, approximately 18 hours after the operations, five patients complained of visual impairment, but they had no pain in their eyes. After full ophthalmologic examinations, they were diagnosed with TASS, but also endophthalmitis was suspected. Treatment for both TASS and endophthalmitis was started. However, when conjunctival culture results were seen to be negative, the systemic antibiotic therapy and intense topical antibiotic therapy for endophthalmitis were ceased. In Tables 1 and 2, both preoperative and postoperative findings of five patients with TASS are shown. The clinical findings and courses of the patients follow. The cases are in the order that the surgery was performed, but between and among them, there were uneventful cases that we did not mention in detail, because there were no problems postoperatively.

\section{Case I}

A female patient 67 years of age with diabetes mellitus and hypertension had bilateral grade 3 nuclear sclerosis, and also panretinal photocoagulation due to proliferative diabetic retinopathy 2 years previously. One week earlier, her right eye had been operated on; she had no problem with that eye. Her best-corrected visual acuity (BCVA) for her left eye was 2/10 preoperatively (Snellen score, decimal), and her intraocular pressure (IOP) was $19 \mathrm{mmHg}$. After her left-eye operation, on the first day she complained of visual impairment, but she had no pain. She had diffuse limbus-tolimbus corneal edema, 3+ white blood cell (WBC), 2+ flare, fibrin and hypopyon in the anterior chamber, the pupil was mid-dilated, the iris was atrophic, there was no reaction in the vitreous, IOP was $24 \mathrm{mmHg}$, and her BCVA was 0.05 (Snellen score, decimal). The patient was treated with topical diclofenac $0.1 \%$ four times a day, moxifloxacin $0.5 \%$ four times a day, prednisolone acetate $1 \%$ every 2 hours daily, and a dorzolamide $\mathrm{HCl}$ and timolol maleate combination twice a day. Steroid therapy was tapered according to the degree of inflammation. After 2 months, the inflammation and corneal edema resolved, and the patient's BCVA was

Table I Preoperative clinical findings

\begin{tabular}{llllllll}
\hline Case & Age & Sex & Eye & Type of cataract & $\begin{array}{l}\text { Systemic } \\
\text { disorder }\end{array}$ & $\begin{array}{l}\text { Intraocular } \\
\text { pressure }\end{array}$ & $\begin{array}{l}\text { Best-corrected visual acuity } \\
\text { (decimal, Snellen score) }\end{array}$ \\
\hline I & 67 & F & OS & Grade 3 nuclear sclerosis & DM HT & $19 \mathrm{mmHg}$ & 0.2 \\
2 & 57 & F & OD & Posterior subcapsular & None & $17 \mathrm{mmHg}$ & 0.3 \\
3 & 71 & F & OS & Cortical & HT & $12 \mathrm{mmHg}$ & 0.3 \\
4 & 69 & M & OD & Cortical & DM & $13 \mathrm{mmHg}$ & 0.4 \\
5 & 73 & M & OS & Grade 3 nuclear sclerosis & HT & $18 \mathrm{mmHg}$ & 0.1 \\
\hline
\end{tabular}

Abbreviations: F, female; M, male; OD, oculus dexter (right eye); OS, oculus sinister (left eye); DM, diabetes mellitus; $\mathrm{HT}$, hypertension. 
Table 2 Postoperative clinical findings (first postoperative day)

\begin{tabular}{|c|c|c|c|c|c|c|c|c|c|}
\hline Case & Corneal edema & $\begin{array}{l}\text { Anterior-chamber } \\
\text { reaction }\end{array}$ & Fibrin & Hypopyon & Pupil & Iris & Vitreous & IOP & $\begin{array}{l}\text { BCVA } \\
\text { (Snellen score) }\end{array}$ \\
\hline I & $\begin{array}{l}\text { Diffuse limbus to } \\
\text { limbus }\end{array}$ & $3+$ WBC, $2+$ flare & + & Present & Mid-dilated & Atrophic & No reaction & $24 \mathrm{mmHg}$ & 0.05 \\
\hline 2 & Diffuse & $2+$ WBC, no flare & - & Absent & Reactive & Normal & No reaction & $21 \mathrm{mmHg}$ & 0.1 \\
\hline 3 & $\begin{array}{l}\text { Diffuse limbus to } \\
\text { limbus }\end{array}$ & 4+ WBC, 4+ flare & + & Present & Mydriatic & Atrophic & No reaction & $27 \mathrm{mmHg}$ & $\mathrm{P}^{+} \mathrm{P}^{+}$ \\
\hline 4 & Diffuse & $2+W B C$, no flare & - & Absent & Reactive & Normal & No reaction & $22 \mathrm{mmHg}$ & 0.1 \\
\hline 5 & $\begin{array}{l}\text { Diffuse limbus to } \\
\text { limbus }\end{array}$ & 4+ WBC, 4+ flare & + & Present & Mydriatic & Atrophic & No reaction & $29 \mathrm{mmHg}$ & $\mathrm{P}^{+} \mathrm{P}^{+}$ \\
\hline
\end{tabular}

Abbreviations: BCVA, best-corrected visual acuity; IOP, intraocular pressure; WBC, white blood cell; PP, perception, projection.

$7 / 10$, the pupil was reactive, and IOP was within normal limits without antiglaucomatous therapy.

\section{Case 2}

A female patient 57 years of age with no systemic disease had a bilateral posterior subcapsular cataract. One week prior, her left eye had been operated on, and she had no problem with that eye. Her BCVA for her right eye was $3 / 10$ preoperatively (Snellen score, decimal), and her IOP was $17 \mathrm{mmHg}$. After her right-eye operation, on the first day she complained of visual impairment and redness in her eye. She had diffuse but not entire corneal edema, 2+ WBC, no flare, no fibrin, no hypopyon in the anterior chamber, the pupil was reactive, the iris was normal, there was no reaction in the vitreous, IOP was $21 \mathrm{mmHg}$, and her BCVA was $1 / 10$. The patient was treated with topical diclofenac $0.1 \%$ four times a day, moxifloxacin $0.5 \%$ four times a day, prednisolone acetate $1 \%$ every 2 hours daily, and a dorzolamide $\mathrm{HCI}$ and timolol maleate combination twice a day. Steroid therapy was tapered according to the degree of inflammation. At the end of 6 weeks, the inflammation and corneal edema resolved, the patient's BCVA was 10/10, and IOP was normal without any treatment.

\section{Case 3}

A female patient 71 years of age with hypertension had bilateral cortical cataracts. Her right eye had been operated on 1 week prior, and she had no problem with that eye. Her BCVA for her left eye was $3 / 10$ preoperatively. Her IOP was $12 \mathrm{mmHg}$ preoperatively. After her left-eye operation, on the first day she complained of no vision at all. She had diffuse limbus-to-limbus corneal edema, 4+ WBC, 4+ flare, fibrin and hypopyon in the anterior chamber, the pupil was mydriatic, the iris was atrophic, there was no reaction in the vitreous, IOP was $27 \mathrm{mmHg}$, and her BCVA was perception positive, projection positive $\left(\mathrm{P}^{+} \mathrm{P}^{+}\right)$. She was treated with topical diclofenac $0.1 \%$ four times a day, moxifloxacin $0.5 \%$ four times a day, prednisolone acetate $1 \%$ every 2 hours daily, a dorzolamide $\mathrm{HCI}$ and timolol maleate combination twice a day, and a systemic oral steroid (methylprednisolone $1 \mathrm{mg} / \mathrm{kg}$ daily and tapered). Corneal edema persisted in spite of this intense therapy, and in the sixth postoperative month, the patient was referred to another center for penetrating keratoplasty. After this operation, her BCVA was $5 / 10$, and she continued antiglaucomatous therapy owing to persistent glaucoma.

\section{Case 4}

A male patient 69 years of age had diabetes mellitus and bilateral cortical cataracts. One week prior, his left eye had been operated on, and he had no problem with that eye. His BCVA for his right eye was $4 / 10$ preoperatively, and his IOP was $13 \mathrm{mmHg}$. After his right-eye operation, on the first day he complained of impaired vision and lid edema. He had diffuse but not entire corneal edema, 2+ WBC, no flare, no fibrin, no hypopyon in the anterior chamber, the pupil was reactive, the iris was normal, no reaction in the vitreous was present, IOP was $22 \mathrm{mmHg}$, and his BCVA was $1 / 10$. He was treated with topical diclofenac $0.1 \%$ four times a day, moxifloxacin $0.5 \%$ four times a day, prednisolone acetate $1 \%$ every 2 hours, and a dorzolamide HCI and timolol maleate combination twice a day. Steroid therapy was tapered according to the degree of inflammation. After 6 weeks, the inflammation and corneal edema resolved, and his BCVA was 10/10; IOP was normal without treatment.

\section{Case 5}

A male patient 73 years of age had hypertension and bilateral grade 3 nuclear sclerosis. His right eye had been operated on 1 week prior, and he had no problem with that eye. His BCVA for his left eye was $1 / 10$ preoperatively, and his IOP was $18 \mathrm{mmHg}$. After his left-eye operation, on the first day he complained of no vision. He had diffuse limbus-to-limbus corneal edema, 4+ WBC, 4+ flare, fibrin and hypopyon in the anterior chamber, the pupil was mydriatic, the iris was 
Table 3 Final outcomes

\begin{tabular}{|c|c|c|c|}
\hline Case & BCVA & IOP & Final outcome \\
\hline I & 0.7 & $15 \mathrm{mmHg}$ & No inflammation, no corneal edema \\
\hline 2 & 1 & $17 \mathrm{mmHg}$ & No inflammation, no corneal edema \\
\hline 3 & 0.5 & $21 \mathrm{mmHg}$ & $\begin{array}{l}\text { Penetrating keratoplasty and } \\
\text { persistent glaucoma }\end{array}$ \\
\hline 4 & I & $16 \mathrm{mmHg}$ & No inflammation, no corneal edema \\
\hline 5 & 0.2 & $24 \mathrm{mmHg}$ & $\begin{array}{l}\text { Trabeculectomy and penetrating } \\
\text { keratoplasty, and optic nerve damage }\end{array}$ \\
\hline
\end{tabular}

Abbreviations: BCVA, best-corrected visual acuity; IOP, intraocular pressure.

atrophic, there was no reaction in the vitreous, IOP was $29 \mathrm{mmHg}$, and his BCVA was $\mathrm{P}^{+} \mathrm{P}^{+}$. He was treated with topical diclofenac $0.1 \%$ four times a day, moxifloxacin $0.5 \%$ four times a day, prednisolone acetate $1 \%$ every 2 hours daily, a dorzolamide HCI and timolol maleate combination twice a day, and a systemic oral steroid (methylprednisolone $1 \mathrm{mg} / \mathrm{kg}$ daily and later tapered). Unfortunately, despite this intensive therapy, corneal edema and glaucoma persisted. In the seventh postoperative month, he underwent both trabeculectomy and penetrating keratoplasty operations in another center. Postoperatively, his BCVA was $2 / 10$, due to glaucomatous damage to the optic nerve. The final outcomes of the patients are shown in Table 3.

We assembled surgeons, nurses, operating room staff, and sterilization staff for a meeting to investigate the cause of the TASS cases. We reviewed surgical instruments, sterilization machines, the solutions, and medications used. Even though we investigated the operation room intensively, the sterilization process, medications used preoperatively and intraoperatively, the operation team, and instruments used, we could not identify any cause for these TASS cases.

\section{Discussion}

The most effective treatment of TASS is to impede its development. ${ }^{12}$ In an outbreak, all steps should be controlled. ${ }^{13}$ However, many times it is not possible to find the causative agent, as in our cases.

Cutler Peck et al analyzed data from 77 questionnaires and 54 site visits. They found that common practices associated with TASS included inadequate flushing of phacoemulsification hand-piece and irrigation/aspiration hand-pieces, use of enzymatic cleansers, detergents at the wrong concentrations, ultrasonic baths, antibiotic agents in balanced salt solutions, preserved epinephrine, inappropriate agents for skin preparation, and powdered gloves. Reuse of single-use products and poor instrument maintenance and processing were other risk factors. ${ }^{4}$
Bodnar et al analyzed data from 130 questionnaires and 71 site visits. They determined that there was a $26 \%$ reduction in sites reporting inadequate hand-piece flushing volumes and a $27 \%$ increase in sites using a deionized/distilled final rinse, a $36 \%$ reduction in the use of preserved epinephrine, and a $36 \%$ reduction in the use of enzymatic detergents. However, there was a $21 \%$ increase in handling of IOLs or instrument tips with gloved hands, a $47 \%$ increase in poor instrument maintenance, and a $34 \%$ increase in ultrasound bath use without adequate routine cleaning. ${ }^{5}$

Moyle et al reported that eleven consecutive patients undergoing phacoemulsification cataract surgery on 2 separate days by the same surgeon had developed TASS on the first postoperative day. They treated the patients with intense topical anti-inflammatory and steroidal drugs. In all patients, active inflammation and corneal edema resolved within 6 weeks, and visual outcome was 20/20. ${ }^{6}$ In our patients, we also started intense topical anti-inflammatory and steroidal and antiglaucomatous drugs. In three patients, active inflammation and corneal edema resolved within 2 months, and their visual acuities increased to $7 / 10,10 / 10$, and 10/10. However, the other two patients underwent penetrating keratoplasty, with one of them undergoing additional trabeculectomy, and their visual outcomes were $5 / 10$ and 2/10, respectively.

Adequate cleaning and flushing of phacoemulsification and irrigating and aspirating hand-pieces is important to prevent TASS development. Both ports of the hand-pieces should be flushed with $120 \mathrm{~mL}$ of sterile distilled or deionized water after each case. ${ }^{14,15}$ The ophthalmic viscoelastic substances remaining within cannulas are denatured by autoclaving, and after entrance into the anterior chamber, they may cause TASS. ${ }^{10,16}$ Enzymatic detergents have some exotoxins that cannot be deactivated by autoclaves, which is why they should not be used for decontamination of the instruments. ${ }^{9}, 17,18$ Ultrasound baths may be colonized with Gram-negative bacteria producing endotoxins that are heat-stable and cannot be deactivated by autoclaves. The instruments can take these endotoxins from a contaminated ultrasonic bath, and thus may cause TASS after entrance into the anterior chamber., ${ }^{4,5,11}$ Intraocular medications used should be preservative-free (like benzalkonium chloride), because these preservatives cause severe endothelial damage. ${ }^{19,20}$ Both powdered and powder-free gloves can cause TASS, which is why IOLs, tips, and surfaces entering the anterior chamber should not be touched with a gloved finger. ${ }^{14}$ Glutaraldehyde and ethylene oxide can cause TASS, so they should not be used in the sterilization process. ${ }^{2,13}$ Intraocular ointment usage also may cause TASS. ${ }^{21}$ 
Disposable devices should be used instead of reusable devices if possible, and disposable devices should not be reused. ${ }^{12,18}$ Ophthalmic instruments should always be cleaned and sterilized separately from other surgical instruments. ${ }^{5}$

In conclusion, TASS is a preventable complication of anterior-segment surgery. Recognition of TASS, differentiating it from endophthalmitis, and starting treatment immediately is important. Controlling all steps in surgery, cleaning and sterilization, and training nurses and other operation teams will help us in the prevention of TASS.

\section{Disclosure}

The authors report no conflicts of interest in this work.

\section{References}

1. Moshirfar M, Whitehead G, Beutler BC, Mamalis N. Toxic anterior segment syndrome after Verisyse iris-supported phakic intraocular lens implantation. J Cataract Refract Surg. 2006;32:1233-1237.

2. Ünal M, Yücel I, Akar Y, Oner A, Altın M. Outbreak of toxic anterior segment syndrome associated with glutaraldehyde after cataract surgery. J Cataract Refract Surg. 2006;32:1696-1701.

3. Holand SP, Morck DW, Lee TL. Update on toxic anterior segment syndrome. Curr Opin Ophthalmal. 2007;18:4-8.

4. Cutler Peck CM, Brubaker J, Clouser S, Danford C, Edelhauser HE, Mamalis N. Toxic anterior segment syndrome: common causes. J Cataract Refract Surg. 2010;36:1073-1080.

5. Bodnar Z, Clouser S, Mamalis N. Toxic anterior segment syndrome: update on the most common causes. J Cataract Refract Surg. 2012; 38:1902-1910.

6. Moyle W, Yee RD, Burns JK, Biggins T. Two consecutive clusters of toxic anterior segment syndrome. Optom Vis Sci. 2013;90:e11-e23.

7. Sengupta S, Chang DF, Gandhi R, Kenia H, Venkatesh R. Incidence and long-term outcomes of toxic anterior segment syndrome at Aravind Eye Hospital. J Cataract Refract Surg. 2011;37:1673-1678.

8. Richburg FA, Reidy JJ, Apple DJ, Olson RJ. Sterile hypopyon secondary to ultrasonic cleaning solution. J Cataract Refract Surg. 1986;12: $248-251$.
9. Parikh C, Sippy BD, Martin DF, Edelhauser JF. Effects of enzymatic sterilization detergents on the corneal endothelium. Arch Ophthalmol. 2002;120:165-172.

10. Liu H, Routley I, Teichmann KD. Toxic endothelial cell destruction from intraocular benzalkonium chloride. J Cataract Refract Surg. 2001; 27:1746-1750.

11. Kreisler KR, Martin SS, Young CW, Anderson CW, Mamalis N. Postoperative inflammation following cataract extraction caused by bacterial contamination of the cleaning bath detergent. J Cataract Refract Surg. 1992;18:106-110.

12. Mamalis N, Edelhauser HF, Dawson DG, Chew J, LeBoyer RM, Werner L. Toxic anterior segment syndrome. J Cataract Refract Surg. 2006;32:324-333.

13. Choi YS, Shyn KH. Development of toxic anterior segment syndrome immediately after uneventful phaco surgery. Korean J Ophthalmol. 2008;22:220-227.

14. Hellinger WC, Bacalis LP, Edelhauser HF, Mamalis N, Milstein B, Masket S. Recommended practices for cleaning and sterilizing intraocular surgical instruments. J Cataract Refract Surg. 2007;33:1095-1100

15. [No authors listed]. Recommended practices for the evaluation and selection of products and medical devices used in perioperative practice setting. Association of Operating Room Nurses. AORN J. 1998;67: 270-272.

16. Kim JH. Intraocular inflammation of denatured viscoelastic substance in cases of cataract extraction and lens implantation. J Cataract Refract Surg. 1987;13:537-542.

17. Carter LM, Duncan G, Rennie GK. Effects of detergents on the ionic balance and permeability of isolated bovine cornea. Exp Eye Res. 1973; 17:409-416

18. Parikh $\mathrm{CH}$, Edelhauser HF. Ocular surgical pharmacology: corneal endothelial safety and toxicity. Curr Opin Ophthalmol. 2003;14: $178-185$.

19. Britton B, Hervey R, Kasten K, Gregg S, McDonald T. Intraocular irritation evaluation of benzalkonium chloride in rabbits. Ophthalmic Surg. 1976;7:46-55

20. Green K, Hull DS, Vaughn ED, Malizia AA Jr, Bowman K. Rabbit endothelial response to ophthalmic preservatives. Arch Ophthalmol. 1977;95:2218-2221.

21. Werner L, Sher JH, Taylor JR, et al. Toxic anterior segment syndrome and possible association with ointment in the anterior chamber following cataract surgery. J Cataract Refract Surg. 2006;32:227-235.
Clinical Ophthalmology

\section{Publish your work in this journal}

Clinical Ophthalmology is an international, peer-reviewed journal covering all subspecialties within ophthalmology. Key topics include: Optometry; Visual science; Pharmacology and drug therapy in eye diseases; Basic Sciences; Primary and Secondary eye care; Patient Safety and Quality of Care Improvements. This journal is indexed on

\section{Dovepress}

PubMed Central and CAS, and is the official journal of The Society of Clinical Ophthalmology (SCO). The manuscript management system is completely online and includes a very quick and fair peer-review system, which is all easy to use. Visit http://www.dovepress.com/ testimonials.php to read real quotes from published authors. 